\title{
Pelatihan Standar Pengelolaan Sekolah Luar Biasa Berbasis Digital untuk Mewujudkan Smart School Society 5.0
}

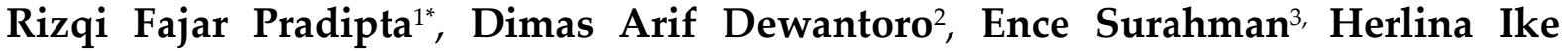 Oktaviani $^{4}$}

1,2,Pendidikan Luar Biasa, Universitas Negeri Malang, Indonesia, 65145

3,4,Teknologi Pendidikan, Universitas Negeri Malang, Indonesia, 65145

E-mail: rizqi.fajar.fip@um.ac.id

DOI: https://doi.org/10.37339/jurpikat.v1i2.284

\section{Info Artikel:}

Diterima :

2020-09-02

Diperbaiki :

2020-09-26

Disetujui :

2020-10-07

Kata kunci: Standar

Pengelolaan Digital, Sekolah

Luar Biasa, Smart School

Society 5.0
Abstrak: Dapodik adalah salah satu alat yang dibuat untuk pengelolaan manajemen sekolah berbasis ICT. Oleh karenanya penting sekali pada era saat ini untuk mendigitalisasi pengelolaan sekolah agar lebih mudah dalam pengawasan dan pengontrolan. Solusi yang diberikan pada dasarnya adalah pemberian pelatihan dalam meningkatkan sumber daya manusia di Sekolah Luar Biasa Dharma Wanita Sidoarjo terkait dengan Teknologi Informasi Komputer serta membantu merancang Blue Print Smart School Society 5.0. untuk SLB - B Dharma Wanita Kabupaten Sidoarjo. Tahapan pelatihan dijabarkan pada bagian Metode Pelaksanaan. Hasil Pengabdian ini berupa pemanfaatan Teknologi Informasi Komputer dimanfaatkan oleh guru dengan melakukan kegiatan pembelajaran, evaluasi pembelajaran, serta hasil atau report Progres siswa dapat dilakukan secara digital, pada tenaga kependidikan (Staff/Tendik) dapat melakukan seluruh proses administrasi seperti pendaftaran siswa, surat menyurat, dan segala bentuk administrasi lainya kedalam bentuk digital, pada kepala sekolah dapat melakukan kontrol presensi, aktifitas pembelajaran guru, serta agenda kegiatan sekolah dalam bentuk digital.

Abstract: Dapodik is a tool designed for ICT-based school management. Therefore, it is very important in the 
Keywords: Digital

Management Standards,

Extraordinary Schools, Smart

School Society 5.0 current era to digitize school management to make it easier to supervise and control. The solution given is basically providing training in improving human resources at the Dharma Wanita Sidoarjo Special School related to Computer Information Technology and helping to design the Blue Print Smart School Society 5.0. for SLB - B Dharma Wanita Sidoarjo Regency. The training stages are described in the Implementation Methods section. The results of this Service in the form of the use of Computer Information Technology are used by teachers by carrying out learning activities, evaluating learning, and results or student progress reports can be done digitally, education personnel (Staff / Tendik) can carry out all administrative processes such as student registration, correspondence, and all other forms of administration in digital form, the principal can control attendance, teacher learning activities, and school activity agendas in digital form.

\section{Pendahuluan}

Keunggulan suatu bangsa tidak lagi bertumpu pada kekayaan alam, melainkan pada keunggulan sumber daya manusia (SDM), yaitu tenaga terdidik yang mampu menjawab tantangan-tantangan yang sangat cepat. Secara keseluruhan, di Indonesia mutu SDM Indonesia saat ini masih ketinggalan dan berada di belakang SDM negara-negara maju dan negara-negara tetangga, seperti Malaysia dan Thailand (Nuraeni, 2010). Kenyataan ini sudah lebih dari cukup untuk mendorong pakar dan praktisi pendidikan melakukan kajian sistematik untuk membenahi atau memperbaiki sistem pendidikan nasional.

Sejalan dengan gagasan desentralisasi pengelolaan pendidikan, maka fungsifungsi pengelolaan sekolah perlu diberdayakan secara maksimal agar dapat berjalan secara efektif untuk menghasilkan mutu lulusan yang diharapkan oleh masyarakat dan bangsa (Kuswandi, 2011). Hal tersebut perlu didukung oleh seperangkat instrument yang akan mendorong sekolah berupaya meningkatkan efektivitas fungsi-fungsi pengelolaannya secara terus-menerus sehingga mampu berkembang menjadi learning organization. Proses pembelajaran TIK di SLB disajikan pada Gambar 1. 


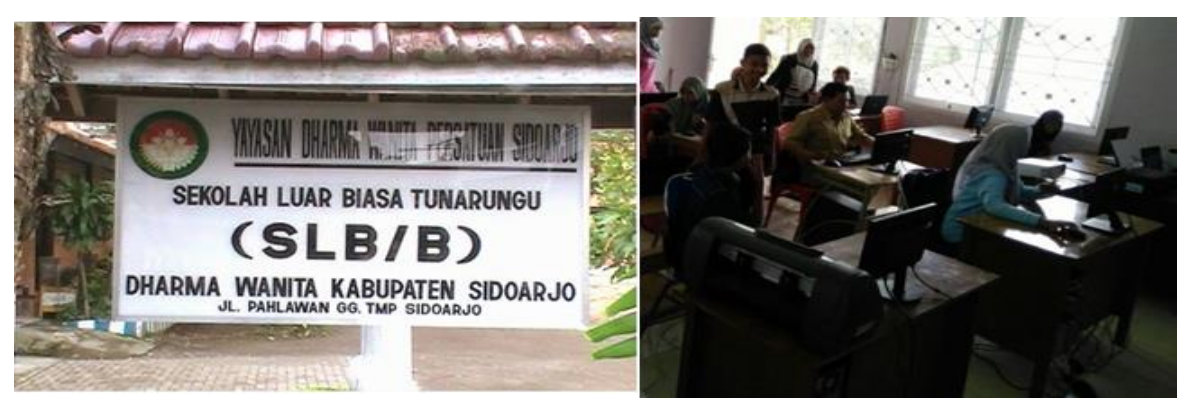

Gambar 1. Foto Kiri adalah Logo SLB, Foto Kanan adalah Proses pembelajaran TIK

Kemajuan teknologi informasi dan komunikasi kini telah mengubah cara pandang dan bertindak masyarakat dalam menghabiskan waktu untuk bekerja dan mengatasi segala permasalahannya. Muncul paradigma baru dalam masyarakat yang mengekspresikan perubahan baru dalam aktifitas kehidupan masyarakat sebagai dampak dari kemajuan TIK. Pada sistem perdagangan dan ekonomi kini muncul e-commerce, ebusiness, e-trading, dan e-shop (Pranata, 2014). Pada sistem pemerintahan muncul e-government, yang kemudian memunculkan bentuk-bentuk baru dalam penyelenggaraan dan pelayanan pemerintahan, seperti: eadministration, e-society, e-health, e-citizen, e-services, edemokrasi, dan e-tendering atau e-procurement (Mumtahana, 2017). Banyak lagi bentuk perubahan lainnya terjadi dalam sendi-sendi kehidupan masyarakat yang dibawa oleh kemajuan TIK, tidak terkecuali, dalam dunia pendidikan. Sedangkan dalam bidang pendidikan saat ini Manajemen berbasis Sekolah (MBS) sudah mulai diterapkan dan hal ini mambatu proses manajemen sekolah dalam mewujudkan tujuan pendidikan (Tabrani, 2013). Proses manajemen sekolah ini kemudian dikolabolasikan dengan perkembangan Teknologi Informasi dan Komunikasi dan hal inimenjadi peluang pengembangan TIK di bidang Pendidikan dengan dimuculkan kan media pembelajaran berbasis TIK dan Pengelolaan pendidikan berbasis TIK yang di keluarkan oleh Kemdikbud yang salah satunya adalah DAPODIK. Dapodik adalah salah satu alat yang dibuat untuk pengelolaan manajemen sekolah berbasis ICT (Yunis, 2017). Oleh karenanya penting sekali pada era saat ini untuk mendigitalisasi pengelolaan sekolah agar lebih mudah dalam pengawasan dan pengontrolan.

Secara sarana dan Prasana di SLB - B Dharma Wanita sudah cukup memadahi dengan tersedianya jaringan wifi dengan kecepatan hingga 100mbps serta jangkauan sinyal yang cukup baik ditambah dengan ketersediaan perangkat keras dalam hal ini Komputer dan Laptop yang spesifikasinya cukup untuk melakukan kegiatan pengelolaan dengan baik. Namun untuk sumber daya yang dimiliki oleh SLB - B Dharma Wanita Sidoarjo belum cukup untuk melakukan sebuah proses mendigitalisasi pengelolaan sistem manajemen di sekolah tersebut. 
Maka dari itu penting adanya pelatihan peningkatan mutu sumber daya manusia di SLB - B Dharma Wanita Sidoarjo sehingga dapat tercipta Standart Pengelolaan Sekolah Luar Biasa Berbasis Digital untuk Mewujudkan Smart School Society 5.0.

Solusi yang diberikan pada dasarnya adalah pemberian pelatihan dalam meningkatkan sumber daya manusia di Sekolah Luar Biasa Dharma Wanita Sidoarjo terkait dengan Teknologi Informasi Komputer serta membantu merancang Blue Print Smart School Society 5.0. untuk SLB - B Dharma Wanita Kabupaten Sidoarjo. Tahapan pelatihan dijabarkan pada bagian Metode Pelaksanaan. Sehingga nantinya setelah pelatihan tersebut diharapkan pemahaman terkait dengan Teknologi Informasi Komputer dapat dimanfaatkan oleh seluruh civitas Sekolah Luar Biasa Dharma Wanita Kabupaten Sidoarjo seperti halnya pada guru dapat melakukan kegiatan pembelajaran, evaluasi pembelajaran, serta hasil atau report Progres siswa dapat dilakukan secara digital, pada tenaga kependidikan (Staff/Tendik) dapat melakukan seluruh proses administrasi seperti pendaftaran siswa, surat menyurat, dan segala bentuk administrasi lainya kedalam bentuk digital, pada kepala sekolah dapat melakukan kontrol presensi, aktifitas pembelajaran guru, serta agenda kegiatan sekolah dalam bentuk digital (Agustin, dkk, 2020). Berdasarkan pengalaman ketua Pengusul yaitu Inovasi Pembelajaran dengan membuat perpustakaan digital berbasis website, kemudian anggota pengusul yang juga berperan dalam membantu membangun SIPEJAR Universitas Negeri Malang diharapkan mampu menjadi sebuah solusi dari permasalahan mitra yang telah disampaikan oleh pelaksana serta mewujudkan Smart School Society 5.0 di Sekolah Luar Biasa Dharma Wanita Kabupaten Sidoarjo.

\section{Metode}

Tahap kegiatan yang akan dilakukan untuk mencapai tujuan dari kegiatan pengabdian kepada masyarakat ini adalah sebagai berikut:

1) Satgas menjalin kerjasama dengan Sekolah Luar Biasa Dharma Wanita Kabupaten Sidoarjo melalui ijin Dinas Pendidikan terkait

2) Satgas mempelajari tentang fasilitas sarana prasarana serta sumber daya manusia Sekolah Luar Biasa Dharma Wanita Kabupaten Sidoarjo terkait dengan teknologi informasi.

3) Satgas bersama mitra memberikan paparan materi tentang konsep Smart School Society 5.0

4) Satgas bersama mitra memberikan paparan materi tentang pengelolaan sekolah berbasis teknologi informasi 
5) Peserta melakukan praktek langsung sesuai dengan materi yang dipaparkan oleh satgas.

6) Satgas bersama mitra melakukan evaluasi pada para peserta yang nantinya akan menghasilkan rekomendasi pada seluruh peserta.

Adapun metode yang digunakan dalam pelatihan meliputi :

1) Ceramah dan Tanya jawab untuk menyampaikan pemahaman pemanfaatan pengelolaan sekolah berbasis teknologi informasi.

2) Praktek.

3) Diskusi untuk melakukan evaluasi rekomendasi pada seluruh peserta.

Evaluasi dalam kegiatan pengabdian kepada masyarakat ini dilakukan terhadap proses pelatihan dan hasil pelatihan (Rizka \& Tamba, 2019).

1) Evaluasi proses pelatihan meliputi :

a) Keaktifan peserta, sebagai indikator dan tolok ukurnya yaitu :

- Kehadiran dilihat dari presensi

- Aktivitas dilihat dari keterlibatan peserta dalam pelatihan

b) Kerjasama, sebagai indikator dan tolok ukurnya yaitu :

- Inisiatif dalam memimpin, mengorganisir peserta lain

- Memunculkan ide kreatif diikuti peserta lain

- Toleransi dan menghargai ide peserta lain

c) Keterampilan, sebagai indikator dan tolak ukurnya yaitu :

- Kecekatan dalam menyelesaikan setiap pekerjaan

- Ketepatan dalam menyelesaikan setiap pekerjaan

- Ketelitian dalam menyelesaikan setiap pekerjaan

- Efisiensi waktu dalam menyelesaikan setiap pekerjaan

2) Evaluasi hasil pelatihan meliputi:

a) Penguasaan teori materi pelatihan, sebagai indikator dan tolok ukurnya yaitu: penerapan teori dalam unjuk kerja.

b) Penguasaan keterampilan kerja, sebagai indikator dan tolak ukurnya yaitu : peserta memenuhi kriteria penilaian tidak kurang dari 80\% dari 4 aspek kriteria penilaian keterampilan.

\section{Hasil dan Pembahasan}

Peserta pada pelatihan ini adalah guru dan tenaga kependidikan sekolah luar biasa (SLB) di Kabupaten Sidoarjo. Lokasi pengabdian kepada masyarakat berada di Sekolah Luar Biasa Putra Mandiri Lebo Sidoarjo yang beralamatkan di jalan raya lebo gedung LBK Lebo Kabupaten Sidoarjo. Jumlah peserta yang hadir berjumlah 25 
orang yang terdiri dari 13 Guru 10 Tenaga Kependidikan, dan 2 Kepala Sekolah. Pada akhir kegiatan Pelatihan ini untuk meningkatkan kompetensi guru dan Tenaga Kependidikan dalam pemanfaatan teknologi digital. Peserta telah memiliki pengetahuan dan pemahaman tentang Administrasi digital, Pembelajaran Digital, Pengawasan Digital sehingga mampu menggunakan atau menerapkan seluruh program pelatihan dalam kegiatan atau aktifitas mereka yang berkaitan dengan kapabilitas mereka masing - masing sesuai dengan potensi yang mereka miliki (Maria \& Soediyono, 2017). Pada akhir kegiatan pelatihan peserta mendapatkan, antara lain; 1) Meningkatnya pemahaman terhadap fungsi teknologi digital serta memiliki ketertarikan untuk mengembangakan kompetensi tersebut bidang sesuai dengan kemampuan yang ada pada mereka; 2) Memahami serta mampu menggunakan dengan baik hasil pelatihan sesuai dengan bidang keahlian yang ada dalam diri peserta.Hasil pretest pemahaman pengelolaan digital disajikan pada Gambar 2.

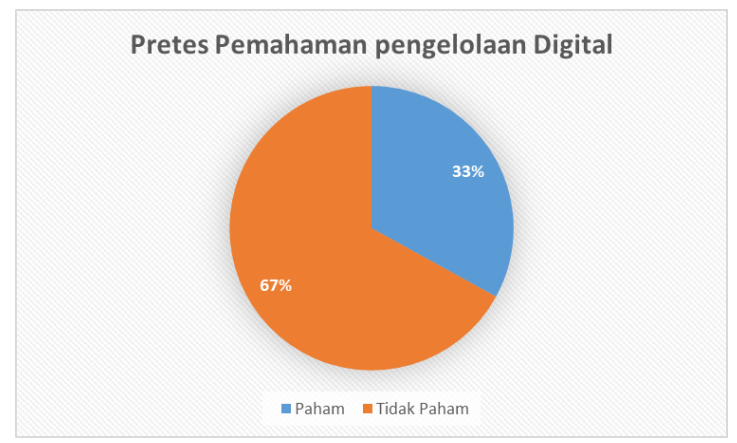

Gambar 2. Diagram Hasil Pretes Pemahaman Pengelolaan Digital Hasil posttest pemahaman pengelolaan digital disajikan pada Gambar 3.

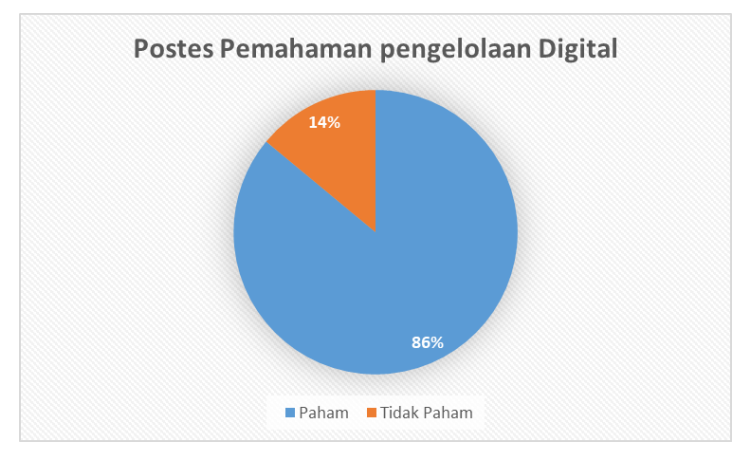

Gambar 3. Diagram Hasil Pretes Pemahaman Pengelolaan Digital

Luaran yang telah dilaksanakan dari program pengabdian kepada masyarakat ini sesuai dengan resentra penelitian dan pengabdian masyarakat Fakultas Ilmu Pendidikan Universitas Negeri Malang yaitu pengembangan Lingkungan Sekolah. Mengunggah laporan kegiatan pada laman berita online 
sehingga dapat di akses secara penuh sebagai bahan rujukan sesuai dengan visi UM sebagai perguruan tinggi rujukan. Luaran tambahan kegiatan sosialisasi adalah mengunggah artikel pada Publikasi Internasional terakreditasi serta Membangun layanan konsultasi apabila ada permalasahan dikemudian hari sebagai dampak dari kegiatan pelatihan. Proses kegiatan pengabdian pelatihan ICT pada Guru SLB disjaikan pada Gambar 4.

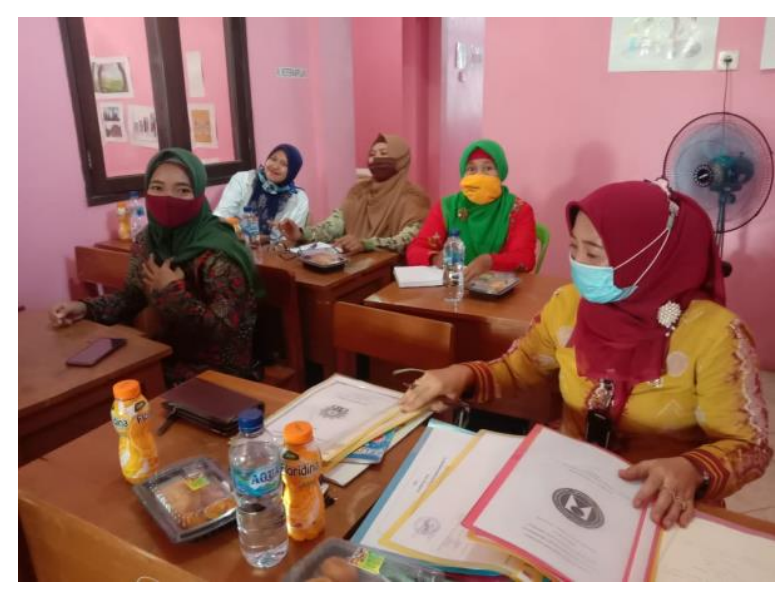

Gambar 4. Proses Kegiatan Pengabdian Pelatihan ICT Pada Guru SLB

\section{Kesimpulan}

Berdasarkan hasil kegiatan pelatihan yang dilaksanakan di Sekolah Luar Biasa Kabupaten Sidoarjo dapat disimpulkan bahwa dalam meningkatkan kompetensi terkait teknologi informasi pada guru dan tenaga pendidikan dapat menggunakan sistem pelatihan atau pemberdayaan dengan metode pelaksanaan yang telah digunakan pada kegiatan ini (Hadi, 2010). Pada dasarnya metode pelaksanaan yang dugunakan sudah sesuai karena dalam penentuannya menggunakan pendekatan dan kajian mendalam dikarenakan karakteristik serta ragam usia sehingga memerlukan upaya adaptasi dalam mentransfer konsep ilmu dan praktek.

\section{Referensi}

Agustin, F., Oganda, F. P., Lutfiani, N., \& Harahap, E. P. (2020). Manajemen Pembelajaran Daring Menggunakan Education Smart Courses. Technomedia Journal, 5(1), 40-53.

Hadi, A. P. (2010). Konsep pemberdayaan, partisipasi dan kelembagaan dalam pembangunan. Yayasan Agribisnis/Pusat Pengembangan Masyarakat Agrikarya (PPMA).

Kuswandi, A. (2011). Desentralisasi pendidikan dalam penyelenggaraan otonomi daerah di Indonesia. governance, 2(1), 69-98. 
Maria, E., \& Sediyono, E. (2017). Pengembangan model manajemen pembelajaran berbasis tik di sekolah dasar. Kelola: Jurnal Manajemen Pendidikan, 4(1), 5971.

Mumtahana, H. A., Nita, S., \& Tito, A. W. (2017). Pemanfaatan Web E-Commerce untuk Meningkatkan Strategi Pemasaran. Khazanah Informatika: Jurnal Ilmu Komputer dan Informatika, 3(1), 6-15.

Nuraeni, Y. (2010). Perancangan Sistem Informasi Penjaminan Mutu Perguruan Tinggi Bidang Sumber Daya Manusia. Jurnal Sistem Informasi, 6(1), 32-43.

Pranata, I. M. A., \& Darma, G. S. (2014). Strategi Penerapan E-Commerce Dalam Meningkatkan Keunggulan Bersaing. Jurnal Manajemen dan Bisnis, 11(1), 6981.

Rizka, M. A., \& Tamba, W. (2019). Pelatihan Evaluasi Program Pendidikan Nonformal Bagi Pengelola Pusat Kegiatan Belajar Masyarakat (PKBM) di Kecamatan Gunungsari Kabupaten Lombok Barat. Paradharma (Jurnal Aplikasi IPTEK), 2(1).

Tabrani, Z. A. (2013). Kebijakan Pemerintah dalam Pengelolaan Satuan Pendidikan Keagamaan Islam (Tantangan Terhadap Implementasi Manajemen Berbasis Sekolah). Serambi Tarbawi, 1(2).

Yunis, R., Ibsah, F. L., \& Arisandy, D. (2017). Analisis Kesuksesan Penerapan Sistem Informasi Data Pokok Pendidikan (DAPODIK) pada SD Kabupaten Batu Bara. Jurnal SIFO Mikroskil, 18(1), 71-82. 